\title{
A Perception Study on Buying Decision Factors of Thai Fish-Shaped Wickerwork (Souvenir) Between Thais and Malaysian Consumers
}

\author{
Graipop Paspirom¹, Yanin Rugwongwan² \\ ${ }^{1}$ Arch D. Student, Multidisciplinary Design Research Program, \\ Faculty of Architecture, King Mongkut's Institute of Technology Ladkrabang (KMITL) 10520, Thailand. \\ ${ }^{2}$ Asst. Prof., Ph.D., Faculty of Architecture, King Mongkut's Institute of Technology Ladkrabang (KMITL) 10520, Thailand \\ Hobbits70@gmail.com
}

\begin{abstract}
Culture can indicate the way of life and the style of society, and the economic fundamentals of different cultures link to perception. Perception factor is one of a people process for making a way of life and path of cultural which is a crucial matter. This study investigates the factors before and after giving information buying decision between Thai and Malaysia with the following objectives: 1.Study the relevant elements of different cultural groups 2.To compare and evaluate the interest to Before and After Giving information product 3.To summaries the results and perceptions that affect decision making
\end{abstract}

Keywords: Perception, Fish-shaped, OTOP, Decision

eISSN: 2398-4287 @ 2018. The Authors. Published for AMER ABRA cE-Bs by e-International Publishing House, Ltd., UK. This is an open access article under the CC BYNC-ND license (http://creativecommons.org/licenses/by-nc-nd/4.0/). Peer-review under responsibility of AMER (Association of Malaysian Environment-Behaviour Researchers), ABRA (Association of Behavioural Researchers on Asians) and CE-Bs (Centre for Environment-Behaviour Studies), Faculty of Architecture, Planning \& Surveying, Universiti Teknologi MARA, Malaysia. https://doi.org/10.21834/e-bpj.v3i9.1492

\subsection{Introduction}

From the preliminary information, the marketing personnel discovered that social class and culture are precious to market segmentation, advertising specification, service providing, and marketing activities. Different social levels will represent differences in needs, purchasing decision, and product consumption. Nowadays, the definition of culture is more complicated since society is multicultural, which means the organisation is in the middle of intercultural communication. A smaller organization in the globalisation era is another form of social culture, and it occurs in the middle of intercultural communication and modern communication technology system that provides the opportunity for humans to communicate with people in different cultures (Jiang, 2006, P.207). The study of the relationship between personal factors and cultures that affect perception are considered to be an important foundation in terms of knowledge, understanding of technical development for tools, or marketing conditions that match the needs of consumer, since there is an explanation for the failure and disappearance of OTOP because the products do not meet the requirements of the consumers who emphasize manufacturing, management, and lack of raw materials. Such an explanation is only one side of the cause. Therefore, the development mechanism in the context of human behaviours is an exciting and challenging thing to know about, such as what are the methods and process development; what are the supportive stuff and what are the things that obstruct the decision in selecting products or goods; and how can we find the solutions for those problems in order to cope and create competitiveness.

eISSN: 2398-4287 @ 2018. The Authors. Published for AMER ABRA cE-Bs by e-International Publishing House, Ltd., UK. This is an open access article under the CC BYNC-ND license (http://creativecommons.org/licenses/by-nc-nd/4.0/). Peer-review under responsibility of AMER (Association of Malaysian Environment-Behaviour Researchers), ABRA (Association of Behavioural Researchers on Asians) and CE-Bs (Centre for Environment-Behaviour Studies), Faculty of Architecture, Planning \& Surveying, Universiti Teknologi MARA, Malaysia.

https://doi.org/10.21834/e-bpj.v3i9.1492 


\subsection{Literature Review}

2.1 Product Perception and Value Assessment follow of architectural perceptions regarding communication, which can be classified into 1. Presentational as objects divided into Presentational Character interpreted from the visible shape or figure, and Representational Character interpreted from the usability or special features to convey the functional value of the items.

2.2 Responsive Meanings are leading to actions related to an emotional condition such as like and dislike (Robert G. Hershberger 1985). Perception is also the way in which an individual views the world around him/her. Hence, two people may have the same idea towards the same stimulus under the same condition, but two people may recognize, select, organize and interpret the said stimulus differently. However, it also depends on base on the individual's processes regarding their needs, values, expectations, and other factors (Schiffman and Kanuk 1991: 146).

2.3 Product Perception and Value Assessment was based on Product Perception and Value Assessment was based on the architectural interpretation of (Robert G. Hershberger,1995), which stated that the definition of architecture could be conveyed in two forms, which are 1) the meaning that expresses the type of physical appearance as objects that can be separated into the presentation of attributes by interpreting from noticeable shape, categorization, or reference from things that are related to oneself. For example size, shape, and unique characteristics. In the aspect of representation, its duty is to convey to users an understanding of the utilization of that thing by interpreting from the usage, the communication of objectives from shapes, or the unique characteristics; 2) the definition that leads to a response that causes an action that is related to emotional conditions, such as like, dislike, want, or don't want. These things are the evaluation and decision that comes from the perception of physical appearance, which leads to a further response.

2.4 Cultural Factor on Consumer Purchase Decisions: The perception in marketing can lead to a purchasing decision. The concept of perception is used to reach the target market. Therefore, the perception of these individuals involves the perception of oneself, the perception of other people, and the perception of the social aspect. The social issue is a stimulus that creates experiences, which are a result of the operation of the sensory system and motivation. These feelings cannot be explained verbally. The experiences can be described and relayed in words. It can be transmitted to other people. Abstractly, the experiences are hard to describe in words, but the characteristic of behaviours can be explained (Saowalak Songsanguan,1997). The consumer behaviours are the study of the behaviours of humans regarding product consumption, usage, and acceptance of the service products. The environment and psychological process influence the consumer decisions. Therefore, the components and variables of the understanding and speculating process must be analysed. Krugman(1986) studied the motivation that causes the purchasing decision by beginning from the stimulus that can occur inside the body or the external stimulus that is known as Buyer's Black Box. It is like a black box that the manufacturer or the seller cannot predict. Therefore, they must try to find out the feelings or thoughts of the buyer that are influenced by the Buyer Characteristics and the Buyer's Purchase Decision. The Buyer Characteristics are influenced by various factors, which are the cultural factor, social factor, personal factor, and the response of the buyers or the Buyer's Purchase Decision.

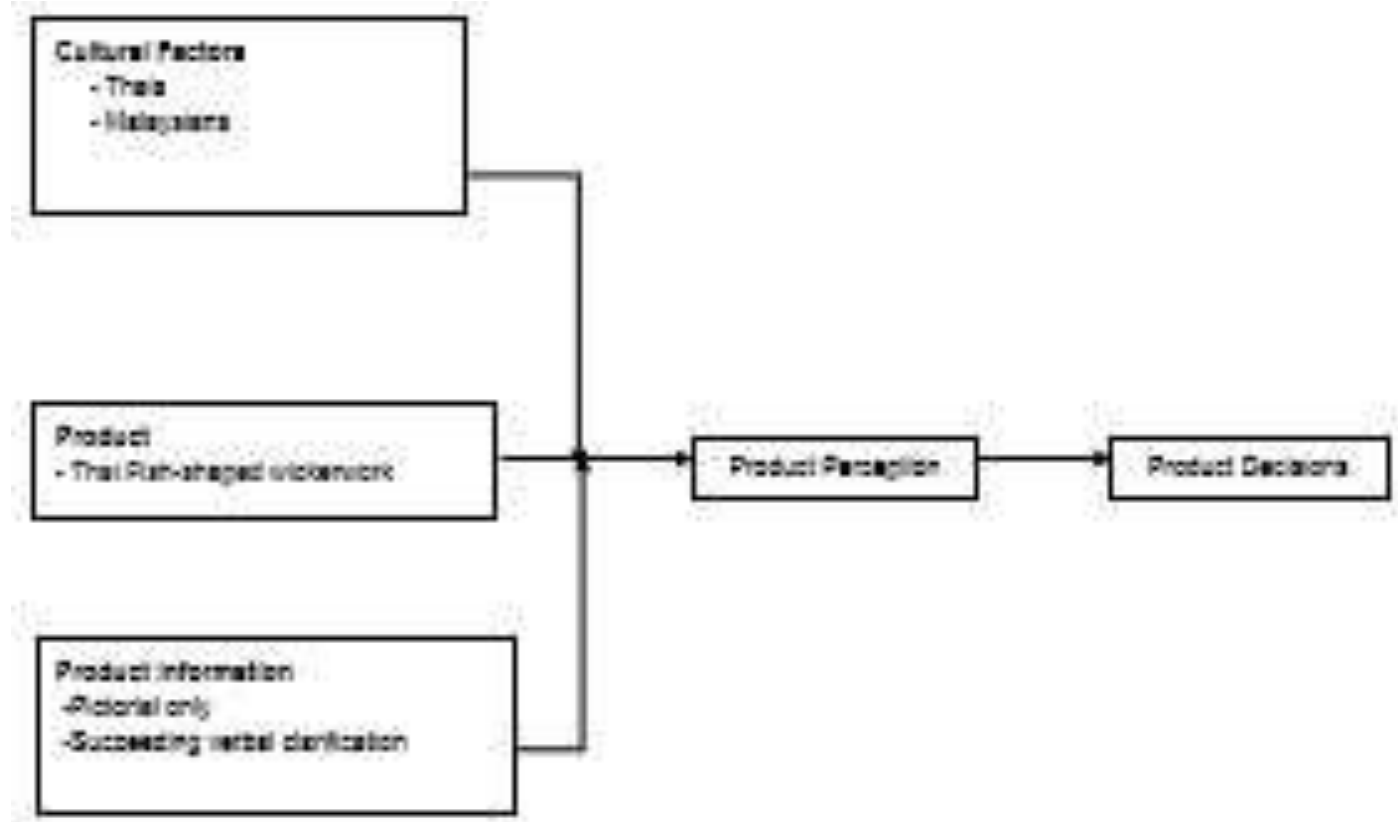

Fig. 1 Research Framework 
2.5 Souvenir Authentic \& Authenticity Perceptions: Guadalupe Revilla and Tim H. Dodd (2003 mentioned that for the authenticity perception in souvenirs, domestic tourists often see true authenticity through the appearances and advantages; whereas, foreign tourists often put more weight on the birthplace or the manufacturing place of the souvenir. There are five aspects of true authenticity, which are 1. Appearance and Advantages; 2 . Authentic Identity and Certification; 3 . Hard to Find or Purchase;4.. Locally Made; and 5. Low Price. Moreover, the tourists can perceive the true genuineness of the souvenirs through its identity and authenticity. They have fine craftsmanship and are created by members in the locality, which reflect the culture and history, decorating by old patterns (Littrell, Anderson, and Brown: 1993 and Cohen: 1988). Moreover, Cohen (1988), Lickorish and Jenkins (1997), and Walle (1988) mentioned that genuineness and authenticity of souvenirs that are in the same direction could guarantee a genuine and authentic product. Or this can be achieved by increasing the aesthetic value or explaining the production process which must be exquisite with a small number of products or rare (Appadurai: 1986). MacCanell (1999) and Goeldner, Ritchie, and Mclntosh (2000) saw that the most important thing for tourists is products that are sold in tourist attractions and are relevant to that place. Moreover, most tourists travel to cities that have differences concerning geography, arts, and cultures. Many people want some things that can remind them of their travelling experience. It might be tiny and easy to carry home (Graburn: 1982).

\subsection{Methodology}

From the research framework was indicated that this research focuses on study consumers' perception of visual perception factors in terms of Composite measure; cognitive and affective leading to the consumer's purchasing decision. The study aims to seek a relation between three variables are elements of Souvenir authentic, perception, and purchase.

They were tested by the perception method through the affective learning approach regarding product visibility before the value assessment with formal and informal perception and compared with cognitive regarding product visibility with environmental identity and local/vernacular historical clarification. The divisional criteria for Thai Fish-shaped wickerwork classification and awareness of the production values were used as factors in the perception test. The researcher identified the points of Thai Fish-shaped wicker work perception as follows: 1. Product Recognition; 2. Product Background Recognition; 3. Products Emphasizing Beauty; 4. Products Focused on Benefits; 5. Value of the Products; 6 . Interest in the Products; 7. Product Attractiveness; and 8 . Product Purchase Probability.

The entire questionnaire for the product groups and responses to the 10 sub-questions was used with the Independent TTest statistical method to test the perception differences among Thais and Malaysians of the perception points between letting the sample groups see pictures with the product information and letting the sample groups only see the pictures. Additionally, Regression Testing was used to test the factors that affect the demand and purchase decision. The researcher set the scale of the questionnaire to 7 levels in accordance with the Likert Scale as follows: Level-1 score refers to the lowest level of perception and Level-7 score refers to the highest level of perception

Table 1: The example of semantic self-report questionnaire

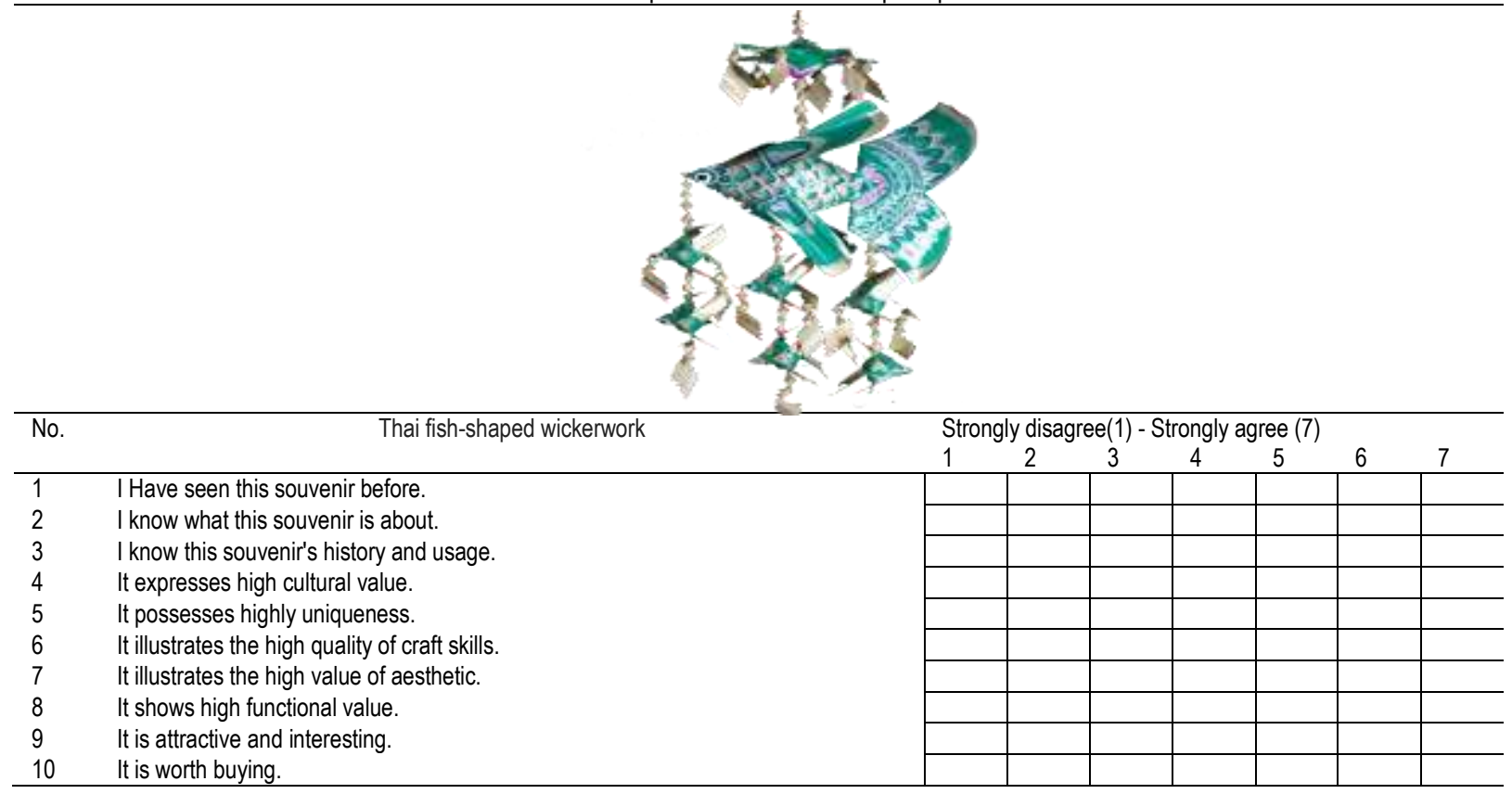




\subsection{Discussion and Analysis}

The analysis results of the general information of the 137-person sample group suggest that: the average age was 22 years old; the average income was 25,000 baht per month; the majority had an undergraduate degree; $50.5 \%$ were Thais; $49.5 \%$ were Malaysians; $61.3 \%$ were female, and $38.7 \%$ were male. Those in this sample group often buy souvenirs from souvenir shops at tourist attractions. The most interesting to purchase belongs to local products, which accounted for $67.0 \%$. Secondly, unique replica models of each region accounted for $47.9 \%$. The critical factors for the consideration before deciding to buy the souvenirs was the local identity, beauty and reasonable price, respectively.

For the analysis results on the differences of the consumers and product values awareness. For the average perception level before and after giving the product information, the results from the comparison of the product perception factors suggested that after providing the additional product information, the majority in the sample group had an increasing level of perception in the same direction which was in the high levels in terms of visual recognition, cultural expression, uniqueness, delicacy, precious beauty, functional values, strangeness (rare to find), nobility, suitability for gifts or collectable keepsakes, exciting and worth buying. The factor with significant change was the sample group that had prior knowledge about the product background, which increased from a previous-low level to a high level.

Table 2: Thai Fish-shaped wickerwork before giving Information

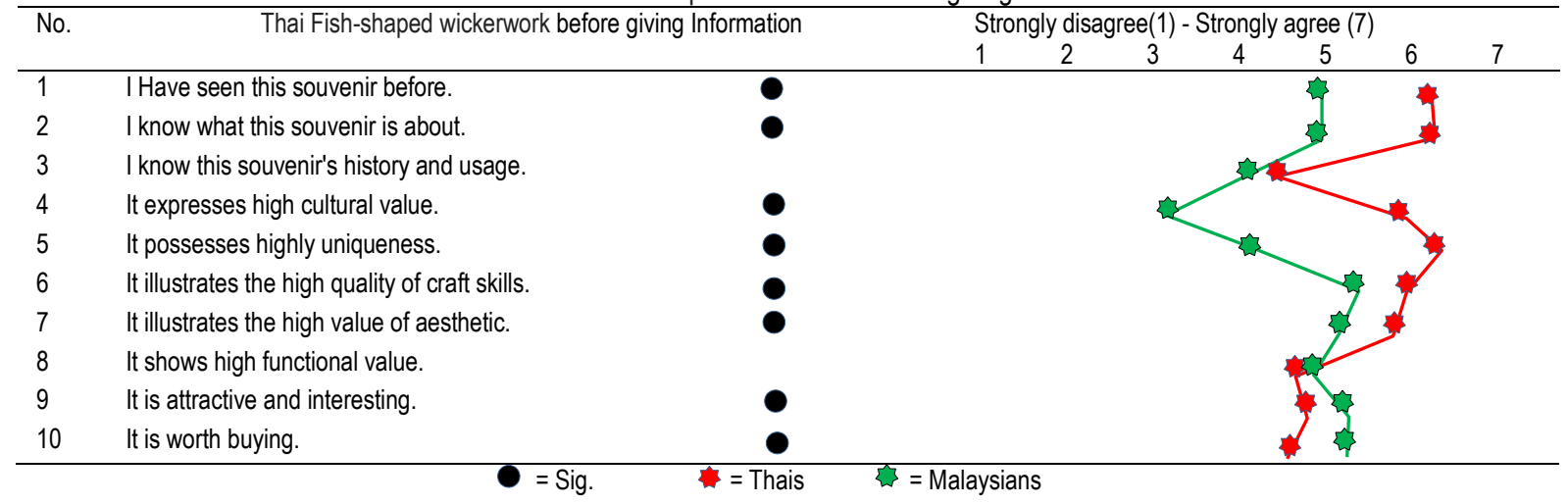

On the point of the impact of racial differences toward the perception of the Thai Fish-shaped wickerwork, it was found that Thai and Malaysian samples have a different perception with a statistical significance level of 0.05 in the item of ((1) I Have seen this souvenir before. (2) I know what this souvenir is about (4) It expresses high cultural value (5) It possesses highly uniqueness. (6) It illustrates the high quality of craft skills. (7) It illustrates the high value of aesthetic. (9) It is attractive and interesting and (10) It is worth buying.

Table 3: Thai Fish-shaped wickerwork after giving Information

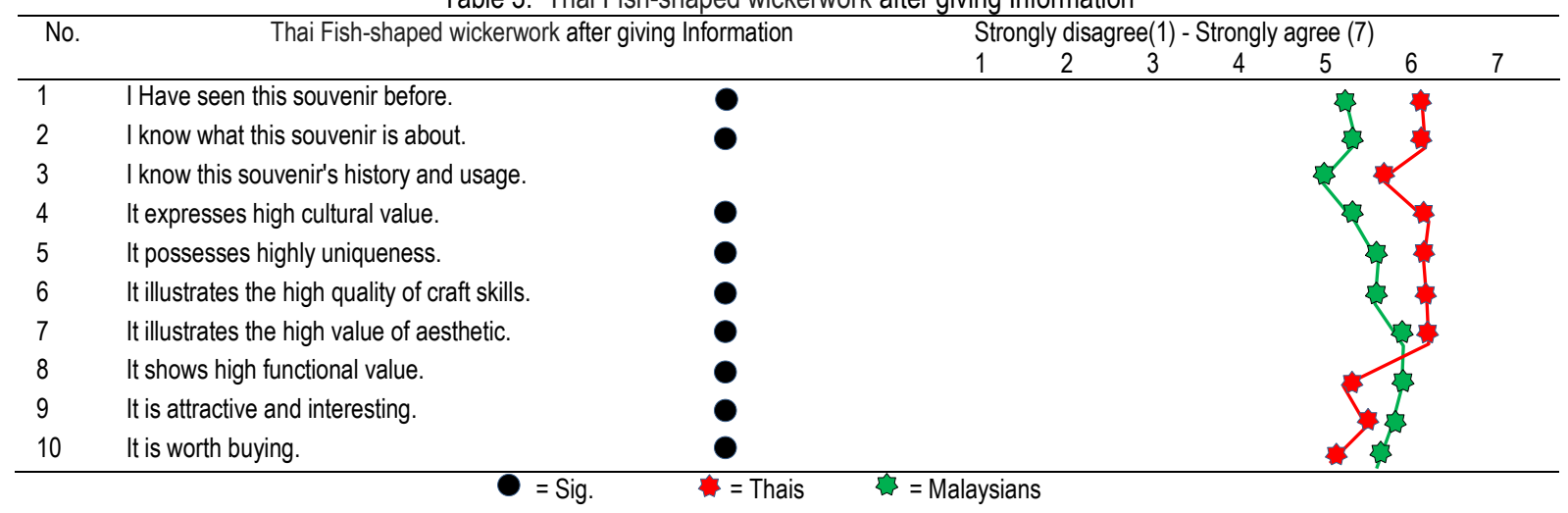

Table 4: Thai Fish-shaped wickerwork before and after giving Information

\begin{tabular}{lll}
\hline No. & \multicolumn{1}{c}{ Thai Fish-shaped wickerwork after giving Information } & Strongly disagree(1) - Strongly agree (7) \\
\hline 1 & I Have seen this souvenir before. & \\
2 & I know what this souvenir is about. & \\
3 & I know this souvenir's history and usage. &
\end{tabular}




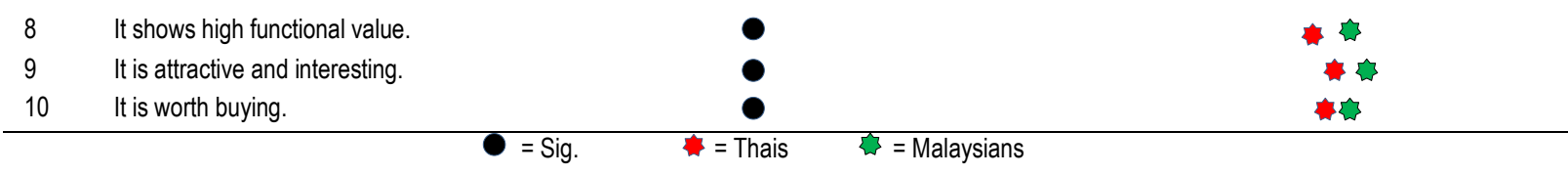

On the point of the impact of racial differences toward the perception of the Thai Fish-shaped wickerwork, it was found that Thai and Malaysian samples have a different perception with a statistical significance level of 0.05 in the item of (1) I Have seen this souvenir before. (2) I know what this souvenir is about (4) It expresses high cultural value possesses highly uniqueness. (6) It illustrates the high quality of craft skills. (7) It illustrates the high value of aesthetic. (8) It shows high functional value. (9) It is attractive and interesting and (10) It is worth buying.

According to the similar result of the perception factor toward Thai Fish-shaped wickerwork, it was found that after receiving additional information about the production, the level of product perception of most samples increased. It also goes in the same direction at a high level. The difference that is significantly noticeable is the increase in the background knowledge of the products. Moreover, the knowledge test regarding the culture can change the value perception of Thai local products between the external appearance (Pre-test) and after receiving the additional information about the product (Post-test) and was found that the perception is different with a statistical significance level of 0.05 in the aspect of (2) I know what this souvenir is about (3) I know this souvenir's history and usage. (4) It expresses high cultural value. (5) It possesses highly uniqueness. (7) It illustrates the high value of aesthetic. (8) It shows high functional value. (9) It is attractive and interesting. (10) It is worth buying.

Table 5: Factors that influence buying decisions Thai Fish-shaped wickerwork (Pictorial Only)

\begin{tabular}{|c|c|c|c|c|}
\hline \multirow{2}{*}{ No. } & \multirow{2}{*}{ Factors that influence buying decisions } & \multicolumn{3}{|c|}{ Thai Fish-shaped wickerwork } \\
\hline & & B & T-test & Sig. \\
\hline 1 & I Have seen this souvenir before. & .045 & .457 & .665 \\
\hline 2 & I know what this souvenir is about. & -.052 & -.542 & .564 \\
\hline 3 & I know this souvenir's history and usage. & .017 & .376 & .715 \\
\hline 4 & It expresses high cultural value. & .015 & .173 & .813 \\
\hline 5 & It possesses highly uniqueness. & -.076 & -.635 & .527 \\
\hline 6 & It illustrates the high quality of craft skills. & -.144 & -1.252 & .245 \\
\hline 7 & It illustrates the high value of aesthetic. & -.019 & -.123 & .851 \\
\hline 8 & It shows high functional value. & .142 & 1.901 & .046 \\
\hline 9 & It is attractive and interesting. & .338 & 3.55 & .000 \\
\hline
\end{tabular}

- $\quad$ statistical significance .05

For Thai Fish-shaped wickerwork, it was found that all independent variables jointly explained the variance of the purchase decision at .05 statistical significance level (Sig. value < .05). The multiple correlation value $(R)$ was .803 and the Coefficient of Determination $\left(\mathrm{R}^{2}\right)$ was .645 , which shows that the independent variables can explain the variance of the dependent variables by $80.3 \%$. When the individual factors were analyzed, it was found that the point in Clause (9), an interesting product, they were factors that had a positive effect on the change of purchase decision at the .05 statistical significance level.

Table 6: Factors that influence buying decisions Thai Fish-shaped wickerwork (Succeeding Clarification)

\begin{tabular}{|c|c|c|c|c|}
\hline \multirow{2}{*}{ No. } & \multirow{2}{*}{ Factors that influence buying decisions } & \multicolumn{3}{|c|}{ Thai Fish-shaped wickerwork } \\
\hline & & $\mathrm{B}$ & T-test & Sig. \\
\hline 1 & I Have seen this souvenir before. & -.037 & -.981 & .333 \\
\hline 2 & I know what this souvenir is about. & .077 & 1.433 & .147 \\
\hline 3 & I know this souvenir's history and usage. & -.118 & -2.334 & .025 \\
\hline 4 & It expresses high cultural value. & .063 & .953 & .327 \\
\hline 5 & It possesses highly uniqueness. & .120 & 1.361 & .185 \\
\hline 6 & It illustrates the high quality of craft skills. & -.028 & -.763 & .448 \\
\hline 7 & It illustrates the high value of aesthetic. & -.019 & -.263 & .882 \\
\hline 8 & It shows high functional value. & .029 & .680 & .481 \\
\hline 9 & It is attractive and interesting. & .538 & 8.594 & .000 \\
\hline
\end{tabular}

- $\quad$ statistical significance .05

For Thai Fish-shaped wickerwork, it was found that all independent variables jointly explained the variance of the purchase decision at the .05 statistical significance level (Sig. value < .05). The multiple correlation value (R) was .857 and the Coefficient of Determination $\left(R^{2}\right)$ was .734 , which shows that the independent variables can explain the variance of the dependent variables by $73.4 \%$. When the individual factors were analyzed, it was found that the point in Clause (1), visual recognition, was the only one with a negative effect on the explanation of the purchase decision at the .05 statistical significance level. While for Clause (3), I know this souvenir's history and usage and (9), interesting products, they were factors that positively affected changes in the purchase decision at the .05 statistical significance level. 


\subsection{Conclusions and Recommendations}

From the study of the cultural differences of the consumers with product value perception, it was found that consumers with different cultures i.e., Thais and Malaysian, have different perceptions of product value. Thai people are quite familiar with the traditional products, also know the product background and cultural expression of the products. From the comparison of product perception between viewing the physical characteristics of the products that act as a medium for communication or giving the product information to see if it could raise the perception of value and to what extent, it was found that the consumers perceived the value and uniqueness of the products differently, after they received additional information which was able to change the product value perception in some cases. In addition, it was found that the perception of the 2 sample groups changed in a better direction since the given product information led to better perception and understanding. The results of this research can also indicate that better perception can influence the purchase decision.

Impact of the cultural differences of consumers toward the value perception of Thai Fish-shaped wickerwork, it was found that the consumers with different cultures, Thai and Malaysian, have a different value perception of Thai Fish-shaped wickerwork. Thai consumers are familiar with Thai Fish-shaped wickerwork, which can be seen from the average that is at a relatively high level. Moreover, Thai consumers know about the background, including the cultural representation of those products, and they can also perceive the identity and the meticulousness that convey the aesthetic value, including the utilisation of the products. However, there are certain things that Thai consumers can see that make the product rare and suitable to be a present and a collection, which make most of the products interesting and valuable to purchase. When considering the value perception of modern products, Thai consumers have a lower perception than Malaysians in many aspects, such as seeing the products before, knowing about the products, and others.

Finally, it was found that the things that show cultural differences affect varied perceptions. Providing the product information is essential in raising the consumers' awareness of the product value and leading to more purchase decisions. There are only 3 perception factors that will result in the purchase decision. Ranked 2. is that the product must present its utilisation, which can indicate the purposes of the product and how to use the product. Ranked 3. is that Thai Fish-shaped wickerwork must be unique. It means that its characteristics must be different from other products in other areas or that it is not imitated. Also, it must have fine craftsmanship that can be a present or a collection

\section{References}

Aaker, J. L. (2000). "Accessibility or Diagnosticity ? Disentangling the Influence of Culture on Persuasion Processes and Attitudes." J Consum Res 26 (4); 340-57.

Basu, K. (1995). "Marketing Developing Society Crafts: A Framework for Analysis and Change." In Marketing in a Multicultural World, edited by J. Costa and B. Bamossy, 257-98. Thousand Oaks: Sage Publications.

Robert, G. Hershberger. (1970). Architecture and Meaning. Journal of Aesthetic Education, Special Issue: The Environment and the Aesthetic Quality of Life $4(4) ; 37-55$

Takada, H, and D. Jain. (1991). Cross-National Analysis of Diffusion of Consumer Durable Goods in Pacific Rim Countries. J Mark 55 (2); $48-54$.

Sangarun, Ratakasikorn and Nij Hinchiranan. (2008). Laksana Thai (Thai Characters).Bangkok: Amarin Printing \& Publishing

Sarath, Simsiri. (2010). Factors Affecting Buyers. Perceptions in Accordance with Marketing Strategy: A Case of Vernacular Thai Product. Social and Behavioral Sciences 5; 1283-7.

Schiffman, Leon G. and Kanuk Leslie Lazar. (1991). Consumer Behavior. 4 th.ed. New Jersey: Englewood Cliffs.

Siriwan and Team. (1998). Newbusiness management. bangkok: Teera Film and Saitext Co.,Ltd

Tanyamai chiarakul. (2014).The Problems and the Adaptation of OTOP to AEC. Business Executive Journal 1; 180 -181

Takada, H, and D. Jain. (1991). Cross-National Analysis of Diffusion of Consumer Durable Goods in Pacific Rim Countries. J Mark 55 (2); $48-54$.

Viboon, Leesuwan. (2003). Folk Art. Bangkok: Amarin Printing \& Publishing.

Viboon, Leesuwan. (2010). Folk Handicrafts: Local Identity. Silpakorn University International Journal.

Yuri Lee, So Young Kim, Yoo-Kyoung Seock, Yunjin Cho.(2009). Tourists' Attitudes Towards Textiles and Apparel-Related Cultural Products: A Cross-Cultural Marketing Study. Tourism Management 30; 724-32. 